\title{
Desenvolvimento das raízes de linho (Linum usitatissimum L.) em dois anos de cultivo sobre Cambissolo Húmico
}

\section{Development of linseed (Linum usitatissimum L.) roots in two years tillage in Inceptsol}

Letícia Salvi Kohn ${ }^{1}$, Carla Eloize Carducci², Kristem do Carmo Rosa Silva ${ }^{1}$, Jânio dos Santos Barbosa ${ }^{3}$, Jonathan dos Santos Fucks ${ }^{1}$, Pedro Antônio Namorato Benevenute ${ }^{4}$.

${ }^{1}$ Acadêmico do curso de Agronomia; Universidade Federal de Santa Catarina - Centro de Curitibanos 2Professora auxiliar; Universidade Federal de Santa Catarina - Centro de Curitibanos

${ }^{3}$ Acadêmico do curso de Engenharia Florestal; Universidade Federal de Santa Catarina - Centro de Curitibanos

${ }^{4}$ Acadêmico do curso de Agronomia; Departamento de Agricultura; Universidade Federal de Lavras.

Artigo enviado em 04/04/2016, aceito em 28/06/2016 e publicado em 13/10/2016

Resumo - A linhaça, semente proveniente do linho, é uma oleaginosa que possui duas variedades: marrom e dourada. Seu cultivo é uma alternativa altamente rentável. É fundamental a avaliação das raízes das culturas para o entendimento do sistema agrícola, porém, o sistema radicular do linho ainda é pouco estudado. Sendo assim, o presente trabalho objetivou analisar a produtividade e a morfologia radicular, comprimento e diâmetro, de duas variedades de linho em dois anos de cultivo. O sistema radicular foi avaliado pelo método da trincheira, onde foram obtidas imagens do perfil do solo sob um gride de amostragem, com posterior processamento das mesmas com o uso do programa Safira para obter as variáveis de diâmetro e comprimento. Para descrever os dados obtidos, foi utilizada a média e o erro padrão da média. No ano de 2014 a linhaça teve boa produtividade e bom desenvolvimento radicular, já em 2015, a produtividade e o sistema radicular de ambas as variedades foram afetados negativamente pelo excesso de precipitação.

Palavras-Chave - linho, sistema radicular, programa Safira.

\begin{abstract}
The linseed, seed from linen, is an oleaginous which has two varieties: brown and gold. The cultivation is an alternative highly profitable. It is critical assessment of crop roots for understanding the farming system, however, the root system of linseed has been little studied. Therefore, the present study aimed analyzing the root system of two varieties of linseed in two years of cultivation. The root system was evaluated by the method of the trench, and were obtained soil profile images in a sampling grid, with subsequent processing thereof with the use of Safira program for obtain the variables of length and diameter. To describe the datas obtained, it was used the mean and standard error of mean. In the year of 2014 the linseed had good productivity and good root development, already in 2015, the productivity and the root system of both varieties was affected negatively by excess of rainfall.
\end{abstract}

Keywords - linen, root system, Safira program.

\section{INTRODUÇÃO}

A linhaça (Linum usitatissimum L.) é a semente proveniente do linho, que é uma planta pertencente ao grupo das oleaginosas. Sendo uma das culturas mais antigas e tradicionais da história (GENSER; MORRIS, 2003), ela possui coloração que varia do marromavermelhado ao dourado. Seu uso pode ser destinado à indústria, alimentação humana e ração para animais. Tendo em vista que possui efeitos funcionais ao organismo humano, a procura pela mesma tem aumentado significativamente nos últimos anos (BORGES, 2009).

Devido sua necessidade de baixas temperaturas para a floração, no Brasil a maior produção está concentrada na região Sul do país (BASSEGIO et al., 2012). Segundo estatísticas da FAO, a linhaça é cultivada em cerca de 2,6 milhões de hectares em todo o mundo, sendo bastante empregada no processo de rotação de culturas com o objetivo de recuperar a degradação física, química e biológica dos solos (SOARES et al., 2009). Por possuir manejo simplificado, é considerada uma planta rústica, não necessitando de alta fertilidade do solo para 
garantir boa produtividade (D'ANTUONO; ROSSINI, 2006). Apesar de tolerar uma grande variedade de solos, a cultura se desenvolve melhor nos que se apresentam bem drenados, com textura média a muito argilosa (HOCKING et al., 1987).

Em relação ao sistema radicular das culturas, sabe-se que o mesmo está diretamente relacionado às características físicas do solo, à genética da planta, e ao teor de água no solo, que interfere positiva ou negativamente na resistência do solo à penetração das raízes. Sabendo-se que o sistema radicular possui fundamental importância nas interações que ocorrem entre o solo, as plantas e os organismos vivos, ter conhecimento sobre sua distribuição é imprescindível para ser realizado o uso mais adequado de práticas de cultivo (COELHO et al., 2001).

O manejo realizado no solo reflete diretamente na distribuição das raízes ao longo do perfil, permitindo maior ou menor exploração do sistema (CARVALHO et al., 1999), e também na absorção de água e aquisição de nutrientes pelas plantas (COELHO et al., 2002). Conforme a arquitetura das raízes, o sistema radicular tende a atingir camadas mais profundas do solo ou localizar-se superficialmente (ABICHEQUER, 2004). Tendo em vista que a linhaça possui baixo custo de produção e alto valor agregado, principalmente quando cultivada em sistema orgânico, ela tem se tornado uma alternativa rentável aos agricultores familiares. Sabendose da importância de estudos relacionados ao sistema radicular, e da escassez dos mesmos para a cultura do linho, o presente trabalho objetivou avaliar a produtividade e morfologia radicular, comprimento e diâmetro de duas variedades de linhaça em dois anos de cultivo.

\section{MATERIAL E MÉTODOS Descrição da área experimental}

O experimento foi implantado em uma área pertencente à Universidade Federal de Santa Catarina Centro de Curitibanos, com coordenadas de $27^{\circ} 16^{\prime} 58^{\prime \prime} \mathrm{S}$ e 50³5'04'W, altitude aproximada de $978 \mathrm{~m}$, e clima subtropical úmido mesotérmico (Cfb) segundo a classificação de Köppen (ALVARES et al., 2013).

Antes da implantação do experimento, março de 2014 , foi realizada a aração do solo, utilizando um arado reversível com 3 discos de 28", numa profundidade de $0,34 \mathrm{~m}$ a fim de realizar a desagregação do solo. No ano de 2014, o experimento foi conduzido em uma área de $150 \mathrm{~m}^{2}$, que foi dividida igualmente em $75 \mathrm{~m}^{2}$ para cada variedade de linhaça cultivada (marrom e dourada), sendo utilizado espaçamento de $0,45 \mathrm{~m}$ entrelinhas e $0,05 \mathrm{~m}$ entre plantas. No ano seguinte, a mesma área foi utilizada, sendo definidos 4 repetições para cada variedade dentro das mesmas, e utilizando espaçamento de $0,34 \mathrm{~m}$ entrelinhas e $0,05 \mathrm{~m}$ entre plantas, para aumentar o estande de plantas em relação ao ano anterior (dados não publicados, EPAGRI Empresa de Pesquisa Agropecuária e Extensão Rural do estado de Santa Catarina). O experimento, em ambos os anos de estudo, teve início no mês de agosto e término no mês de dezembro com a colheita da cultura, sendo que a planta possui ciclo de, aproximadamente, 120 dias. As semeaduras foram realizadas manualmente em sistema de cultivo mínimo, e nenhum trato cultural químico foi utilizado ao longo do cultivo.

O solo da área foi classificado como Cambissolo Húmico Háplico (EMBRAPA, 2013), derivado de basalto, e apresentava boa fertilidade. Através do método da pipeta (EMBRAPA 2011), verificou-se que o solo possuía como característica o elevado conteúdo de argila, sendo que os valores encontrados estão apresentados na tabela 1 .

Tabela 1. Análise granulométrica do Cambissolo Húmico em duas profundidades sob variedades de linho marrom e dourado.

\begin{tabular}{|c|c|c|c|c|c|c|}
\hline \multirow[t]{2}{*}{ Variedades } & Argila & $\begin{array}{c}\text { Areia } \\
0-0,10 \mathrm{~m}\end{array}$ & Silte & Argila & $0,10-0,20 \mathrm{~m}$ & Silte \\
\hline & & ......... & ....... & ....... & ...... & \\
\hline Marrom & 648 & 61 & 291 & 656 & 76 & 268 \\
\hline Dourada & 623 & 62 & 315 & 578 & 78 & 345 \\
\hline
\end{tabular}




\section{Amostragem de solo e análises}

Durante o ciclo da linhaça, foi realizado o monitoramento de umidade do solo para detectar possíveis déficits hídricos, através da coleta de amostras de solo com o auxílio do trado holandês, que eram realizadas semanalmente e após cada ocorrência de precipitação pluviométrica. $\mathrm{O}$ monitoramento foi realizado na profundidade de $0-0,05 \mathrm{~m}$.

Para a avaliação do sistema radicular, no ano de 2014 foram escolhidas, aleatoriamente, três plantas de cada variedade para o estudo das raízes. Em 2015, foram utilizadas duas plantas em cada bloco, sendo que foi amostrada uma planta da variedade marrom e outra da variedade dourada dentro de cada uma das quatro repetições.

Foi utilizado o método da trincheira pelo estudo do perfil cultural, onde, em cada planta selecionada foram abertas trincheiras longitudinais na linha de cultivo, tendo uma planta no centro da trincheira (com dimensões de 0,30 $\mathrm{m}$ de largura x 0,20 $\mathrm{m}$ de profundidade). O solo ao longo da parede da trincheira foi escarificado com a finalidade de expor as raízes, que posteriormente receberam uma fina camada de tinta amarela para elevar o contraste de cor entre elas e o solo (cor bruno). Sequencialmente, foi colocado um gride com as mesmas dimensões da trincheira (formado por quadrículas de $0,05 \mathrm{~m} \mathrm{x} \mathrm{0,05}$ $\mathrm{m}$, totalizando 24 unidades amostrais) em contato com a parede e sobre as raízes. A figura a seguir apresenta uma das imagens do gride de amostragem para visualização das quadrículas, onde foram contabilizadas as raízes do linho. A trincheira possuía as seguintes dimensões: $30 \mathrm{~cm}$ de largura x $20 \mathrm{~cm}$ de profundidade.

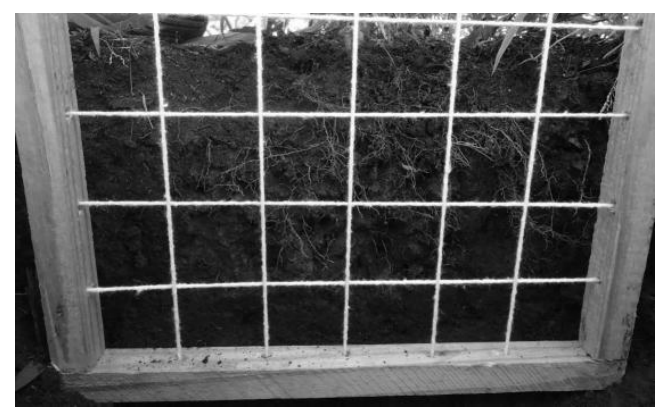

Figura 1. Gride de amostragem sobre as raízes do linho para aquisição de imagens digitais.

Foram adquiridas imagens digitais 2D da parede com as raízes expostas por meio de uma câmera digital com resolução espacial de 16 megapixels. As imagens foram corrigidas e alinhadas com o uso do software Adobe Photoshop CS5 12.0.4, e em seguida processadas no programa Safira, desenvolvido pela Embrapa (JORGE; SILVA, 2010). As raízes foram analisadas nas profundidades de $0-0,10 \mathrm{~m}$ e 0,10-0,20 $\mathrm{m}$ quanto ao seu diâmetro e comprimento, em milímetros.

\section{Análise estatística}

Com a finalidade de descrever a variabilidade observada e indicar a imprecisão associada à estimativa dos dados referentes ao diâmetro e comprimento, foi utilizada a média e o erro padrão da média para confecção das figuras.

\section{RESULTADO E DISCUSSÃO}

A partir dos resultados obtidos referentes às raízes, verificou-se que no ano de 2014, 60\% delas estavam concentradas na camada de $0-0,10 \mathrm{~m}$ no perfil do solo, e no ano de 2015, $80 \%$ se concentrou nesta mesma camada. Referente aos dados de diâmetro pôde-se notar que no ano de 2014, os valores encontrados foram próximos em ambas as profundidades estudadas. Já para a variedade marrom, verificou-se um menor diâmetro na camada de 0,10 0,20 m. Em 2015, os valores de diâmetro encontrados foram maiores em relação aos encontrados no ano de 2014 para ambas as variedades. Porém, no segundo ano de estudo, as variedades e as profundidades não apresentaram grande variação entre os valores encontrados (em torno de 0,80 a $0,90 \mathrm{~mm}$ ), o que pode ser visualizado na figura 2.

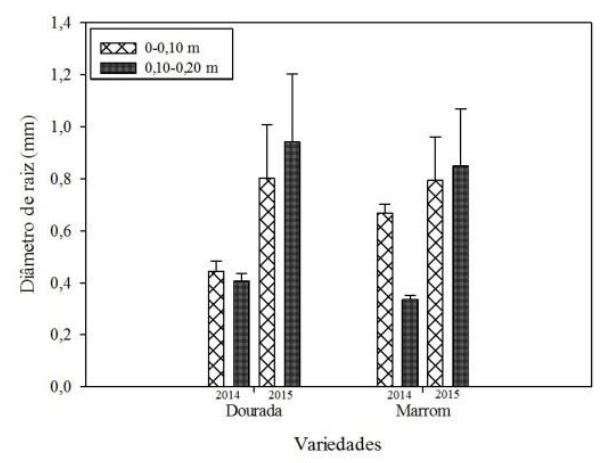

Figura 2. Valores médios e erro padrão da média para o diâmetro $(\mathrm{mm})$ das raízes de linho marrom e dourado

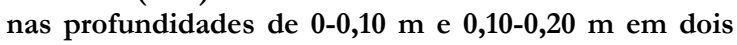
anos de cultivo.

Devido à grande disponibilidade hídrica da região, e sabendo-se que as raízes tendem a se 
concentrar nas camadas mais superficiais do solo quando há grande oferta de água, justifica-se a maior concentração das raízes nesta camada, além de que, quanto maior a quantidade de raízes finas (menor diâmetro), maior será a quantidade de água que a planta conseguirá absorver (JESUS et al., 2006).

Além da maior concentração de raízes na primeira camada de solo $0-0,10 \mathrm{~m}$, o comprimento das raízes também foi maior nessa profundidade. Observou-se que a exploração radicular da cultura da linhaça se limita aos $0,20 \mathrm{~m}$ de profundidade. Pode-se observar na Figura 2, que a variedade de linhaça marrom apresentou maior comprimento $(\mathrm{mm})$ das raízes tanto no ano de 2014 quanto no ano de 2015, o que pode estar relacionado com a época de execução do experimento, onde o clima se apresentou quente e úmido, sendo estas as condições em que a variedade marrom possui maior adaptabilidade (NOVELLO; POLLONIO, 2011), permitindo assim, maior exploração do solo em busca de água e nutrientes pela variedade.

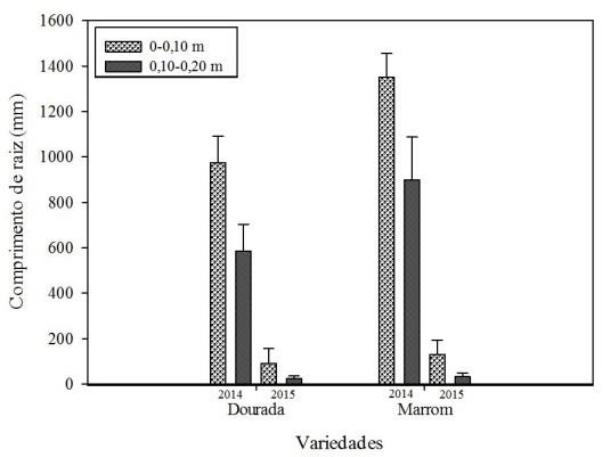

Figura 3. Valores médios e erro padrão da média do comprimento $(\mathrm{mm})$ das raízes de linho marrom e dourado nas profundidades de $0-0,10 \mathrm{~m}$ e $\mathbf{0 , 1 0 - 0 , 2 0 ~ m ~}$ em dois anos de cultivo.

É importante ressaltar também, que pode haver diferença entre as variedades de planta em relação à sua capacidade de absorver nutrientes devido à variação na magnitude e morfologia do sistema radicular (BATISTA et al., 2016), ressalta-se que quanto mais fina a raiz, mais água a planta consegue absorver, devido à menor espessura da parede celular e portanto, maior permeabilidade da membrana (JESUS et al., 2006).

A retenção de água no solo é imprescindível para o desenvolvimento dos vegetais, sendo característica específica de cada solo e resultado da ação de diversos fatores como o conteúdo e mineralogia da fração argila (FERREIRA et al., 1999), teor de matéria orgânica e organização estrutural do solo (REICHARDT, 1988). A exploração vertical das raízes pode ser limitada pela existência de camadas compactadas no solo, textura argilosa, alta densidade na semeadura e altas concentrações de nutrientes próximos à superfície do solo (MATSUO; HOSHIKAWA, 1993), ou devido à abundância de fornecimento da água em anos atípicos como nos que ocorrem o fenômeno 'El niño', que é caracterizado pelo acúmulo de águas mais quentes do que o normal na costa oeste da América do Sul, tendo como consequência o aumento do índice de chuvas na costa oeste da América do Sul (SILVA, 2000).

No ano de 2014, nos meses de agosto a setembro o solo permaneceu em sua capacidade de campo (Figura 3). Houve dois déficits hídricos, que ocorreram nos meses de outubro e dezembro, o que não afetou a produção, pois na época de maior exigência por água (florescimento - enchimento de cápsulas), coincidiu com o mês de novembro, onde a água estava prontamente disponível à cultura. As raízes do linho puderam se desenvolver bem, tendo bom aprofundamento das mesmas, para maior exploração do sistema edáfico.

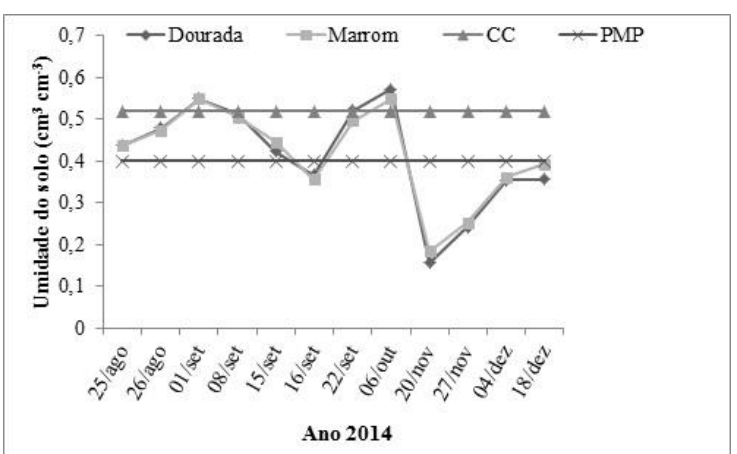

Figura 4. Monitoramento da umidade de um Cabissolo Húmico Háplico sob cultivo de duas variedades de linho (marrom e dourado) ao longo do ciclo da cultura no ano de 2014.

Já no ano de 2015, de agosto a setembro o solo esteve no estado de ponto de murcha permanente, afetando negativamente a cultura na época de emergência das plântulas. A partir do mês de outubro, iniciou-se $O$ período de altas precipitações pluviométricas devido ao fenômeno El Niño, fazendo com que o solo permanecesse com conteúdo elevado de água no solo (Figura 5). Devido ao alto conteúdo de argila, o mesmo possui uma maior porosidade total, que contribui para o desenvolvimento das raízes. Porém, tendo ocorrido grande acúmulo de água na camada superficial em decorrência do fenômeno 
climático, as raízes não se desenvolveram verticalmente, apresentando pequeno comprimento e afetando negativamente a produtividade (Figura 5).

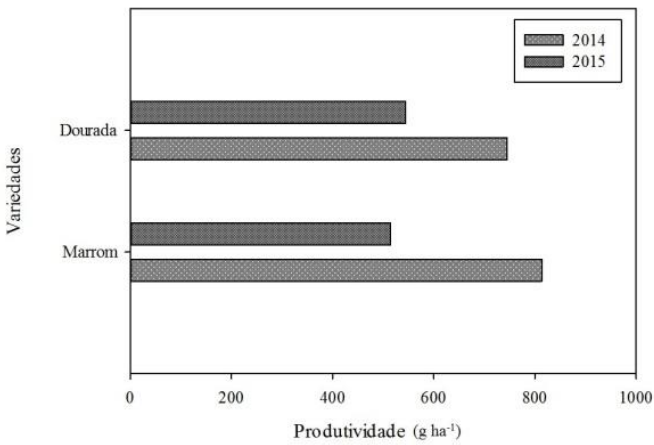

Figura 5. Valores de produtividade média pelo peso de mil sementes $(\mathrm{g})$ em um hectare das variedades de linho marrom e dourado nos anos de 2014 e 2015.

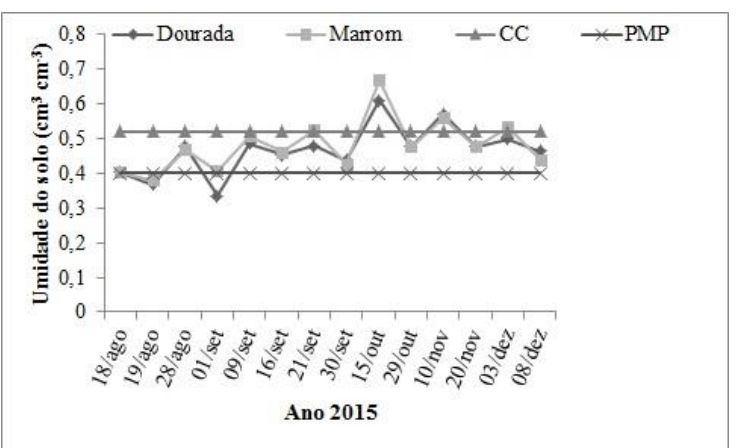

Figura 6. Monitoramento da umidade de um Cambissolo Húmico Háplico sob cultivo de duas variedades de linho (marrom e dourado) ao longo do ciclo da cultura no ano de 2015 .

A partir do desenvolvimento do trabalho em dois anos de cultivo com características climáticas diferentes, fica explícita a relevância de estudos relacionados ao sistema radicular das culturas, e da importância de serem adotados sistemas de manejo de solo que resultem em condições favoráveis para o crescimento e atividade das raízes (ABICHEQUER, 2004), tendo em vista que são órgãos determinantes da nutrição vegetal.

Ficou evidente também a necessidade de eficiência do sistema radicular, para não haver limitações ao rendimento das culturas vegetais. Apesar de a linhaça ser uma planta rústica e não apresentar sintomas quando há ocorrência de pequenos déficits hídricos, a mesma não apresentou boa produtividade e o desenvolvimento radicular caiu drasticamente em condições de excesso de umidade no solo.

\section{CONCLUSÃO}

As raízes do linho se concentram até $0,20 \mathrm{~m}$ de profundidade, especialmente quando cultivado em solo com elevado conteúdo de água.

A variedade de linho marrom apresenta maior comprimento e diâmetro de raízes em ambas as profundidades e ambos os anos de estudo. O excesso hídrico sobre a cultura prejudicou o desenvolvimento e a exploração radicular da cultura, bem como sua produção, para ambas as variedades.

\section{AGRADECIMENTOS}

O presente trabalho foi realizado com o apoio institucional da Universidade Federal de Santa Catarina - Centro Universitário de Curitibanos.

\section{REFERÊNCIAS}

ABICHEQUER, A. D. Morfologia e distribuição de raízes de arroz irrigado por inundação e sua relação com a absorção de nutrientes e o rendimento de grãos. 2004. 66 f. Tese (Doutorado em Ciência do Solo) - Faculdade de Agronomia da UFRGS. Universidade Federal do Rio Grande do Sul, Porto Alegre - RS.

ALVARES, C. A.; STAPE, J. L.; SENTELHAS, P. C.; GONÇALVES, J. L.; SPAROVEK, G. Köppen's climate classification map for Brazil. Meteorologische Zeitschrift, v. 22, p. 711-728, 2013.

BASSEGIO, D.; SANTOS, R. F.; NOGUEIRA, C. E. C.; CATTANEO, A. J.; ROSSETTO, C. Manejo da irrigação na cultura da linhaça. Acta Iguazu, v. 1, n. 3, p. 98-107, 2012.

BATISTA, R. O.; FURTINI NETO, A. E.; DECCETTI, S. F.; VIANA, C. S. Morfologia radicular e cinética de absorção de nutrientes por clones de CedroAustraliano. Revista Caatinga, Mossoró - RN, v. 29, n. 1, 2016.

BORGES, J. T. S. Avaliação tecnológica de farinha mista de trigo e de linhaça integral e sua utilização na elaboração de pão de sal. 2009. 109 p. Dissertação (Pós-graduação em Ciência e tecnologia de alimentos) - Universidade Federal de Viçosa, Minas Gerais, 2009. 
CARVALHO, J. E. B.; SOUZA, L. S.; JORGE, L. A. C.; RAMOS, W.; COSTA NETO, A. O.; ARAÚJO, A. M. A.; LOPES, L.; JESUS, M. Manejo de coberturas de solo e sua interferencia no desenvolvimento do sistema radicular da laranja pêra. Revista Brasileira de Fruticultura, Jaboticabal, v. 21, n. 2, p. 140-145, 1999.

COELHO, E. F.; OLIVEIRA, F. das C.; ARAÚJO, E. C. E.; VASCONCELOS, L. F. L. Distribuição de raízes de laranja "Pêra" sob sequeiro e irrigação por microaspersão em solo arenoso. Pesquisa Agropecuária Brasileira, Brasília, v. 37, n. 5, p. 603-611, 2002.

D'ANTUONO, L. F.; ROSSINI, F. Yield potential and ecophysiological traits of the Altamurano linseed (Linum usitatissimum L.), a landrace of Southern Italy. Genetic Resourcers and Crop Evolution, p. 65-75, 2006.

EMBRAPA, 2011. Empresa Brasileira de Pesquisa Agropecuária. Solos. Manual de métodos de análise de solo. EMBRAPA - SPI, 225 p.

EMBRAPA, 2013. Empresa Brasileira de Pesquisa Agropecuária. Solos. Sistema Brasileiro de Classificação de Solos. EMBRAPA - SPI, 412 p.

FERREIRA, M. M.; FERNANDES, B.; CURI, N. Influência da mineralogia da fração argila nas propriedades físicas de Latossolos da região Sudeste do Brasil. Revista Brasileira de Ciência do Solo, v. 23, n.3, p. 515-524, 1999.

GENSER, A. D.; MORRIS, N. D. History of cultivation and uses of flaxseed. In MUIR, A. D.; WESTCOTT, N. D. Flax - The genus Linum. Taylor and Francis. London, 2003.

GUZMÁN-SILVA, M. A. Avaliação dos efeitos da semente de linhaça quando utilizada como fonte de proteina nas fases de crescimento e manutenção em ratos. Revista de Nutrição, v. 22, n. 4, p. 1 - 9, Campinas - SP, 2009.

HOCKING, P. J.; RANDALL, P. J.; PINKERTON, A. Mineral nutrition of linseed and fiber flax. Advances in Agronomy, v. 41,p.221-296. 1987.

JESUS, A. M. S.; CARVALHO, S. P.; SOARES, Â. M. Comparação entre sistemas radiculares de mudas de coffeeArábica obtidas por estaquia e por sementes. Coffee Science, v. 1,n. 1 p. 14-20, 2006.
JORGE, L. A.; SILVA, D. J. C. B. Safira: manual de utilização. São Carlos: Embrapa CPDIA, 2010, 29 p.

MATSUO, T.; HOSHIKAWA, K. Science of the rice plant. Tokyo: Food and Agriculture Policy Research Center, v. 1, n., p. 161-186, 1993.

NOVELLO, D.; POLLONIO, M. A. R. Caracterização $e$ propriedades da linhaça (Linum usitatissimum L.) e subprodutos. B. CEPPA, Curitiba, v. 29, n. 2, p. 317-330, 2011.

REICHARDT, K. Capacidade de campo. Revista Brasileira de Ciência do Solo, v. 12, p.211-216, 1988.

SILVA, J. de F. da. El Niño, o fenômeno climático do século. 139 p. 2000.

SOARES, L. L.; PACHECO, J. T.; BRITO, C. M.; TROINA, A. A.; BOAVENTURA, G. T.; GUZMÁN-SILVA, M. A. Avaliação dos efeitos da semente de linhaça quando utilizada como fonte de proteína nas fases de crescimento e manutenção em ratos. Revista de Nutrição, v. 22, n. 4, p. 1-9, 2009. 